\title{
Artigo
}

Resumo

O presente artigo visa discutir, a partir do filme Hoje en quero voltar sozinho, do diretor brasileiro Daniel Ribeiro, a maneira como a Psicanálise pensa a sexualidade bumana, encarando-a sempre como uma construção. Para essa reflexão, serão destacados três aspectos do filme: o despertar para a homossexualidade do protagonista, sua cegueira e sua passagem pela adolescência. Esses aspectos serão relacionados entre si através de conceitos de Freud e Lacan que abordem a relação entre a pulsão sexual e seu objeto.

Descritores: cinema; pulsão sexual; homossexualidade; adolescência; psicanálise.

\section{O INTERCÂMBIO IMPOSSÍVEL DA ADOLESCÊNCIA: ANÁLISE PSICANALÍTICA SOBRE O DESPERTAR DA SEXUALIDADE POR MEIO DO FILME "HOJE EU QUERO VOLTAR SOZINHO" DE DANIEL RIBEIRO}


bissexual e transgêneros), realizado em outubro de 2014. O filme narra a história do adolescente cego, Leonardo (Guilherme Lobo), que se descobre apaixonado por um novo aluno de classe. A construção de sua sexualidade homossexual justifica a inserção do longa no festival de Hamburgo. No entanto, o conflito vivido pelo adolescente - e a maneira como a condição visual da personagem poetiza a trama - revela algo da sexualidade que ultrapassa a temática do festival e aponta para a sexualidade de todos os seres humanos, tenham ou não optado por uma orientação homossexual, bissexual ou por uma identidade de gênero trans. Afinal, como já apontava Freud (1905/1996) no início do século XX, o caminho que Leonardo (Guilherme Lobo) percorre às cegas, todos nós temos que percorrer - também nós sempre um pouco às cegas.

Se nos demais animais podemos supor alguma resposta eficaz herdada filogeneticamente para seus instintos sexuais, no homem, tanto o objeto para sua pulsão sexual como a posição que ele ocupará na partilha dos sexos terão de ser construídos. Isso implica um trabalho a ser feito desde a infância até a adolescência, quando algo dessa natureza se estabiliza. Mas evidentemente isso não quer dizer que o trabalho cessa na adolescência, a construção da sexualidade, tanto a da personagem do filme como a de todos nós, é trabalho constante que atravessa as diferentes identificações sociais e escolhas objetais que fazemos durante toda a vida.

Mesmo tendo servido de tema para diversas obras de arte e trabalhos acadêmicos, essa construção da sexualidade humana de modo geral, e de uma orientação homossexual específica, já apresenta, por si só, uma grande relevância. No entanto, o filme ganha um contorno especial quando explora metaforicamente a disjunção denunciada por Freud (1905) entre a pulsão sexual e seu objeto por meio da cegueira do adolescente Leo. Sem poder enxergar os objetos que o cercam e tendo, portanto, que fazer suas escolhas sem contar com alguns importantes traços imaginários que a sociedade empresta ao que é masculino e feminino (como cores e estilos de vestimentas, uso de adereços, traços fisiológicos etc.), Leo se apoia em outras imagens sensoriais para tal construção: o cheiro do moletom, a voz ao pé do ouvido no escuro do cinema, o toque na pele.

A deficiência visual é uma particularidade da personagem, no entanto, uma obra de arte se distingue principalmente pelo o que ela pode alcançar para além de suas especificidades, ainda que através delas. Como aponta Schopenhauer, a verdadeira obra de arte faz do 
particular, "que era na torrente fugidia uma parte ínfima a desaparecer", um representante do todo, "um equivalente no espaço e no tempo do muito infinito" (Schopenhauer, 2003, p. 59). Nesse sentido, seria interessante mostrar como o particular do filme revela uma verdade que serve para todos nós, já que fazemos nossas escolhas sexuais tateando, no escuro, os objetos que a condição humana nos colocou em relação ao alvo de nossa sexualidade.

Também é característica importante do filme a passagem pela puberdade. A Psicanálise aprendeu, desde Freud, que a puberdade se apresenta como um momento de recolocação da sexualidade que foi arrefecida no período de latência. Na puberdade, as perguntas sobre a sexualidade que se iniciaram na infância são reatualizadas, e a falta de uma resposta definitiva para elas traz uma crise que nossa sociedade aprendeu a chamar de adolescência. Ora, não é pouco emblemático que as descobertas de Leo, assim como outros conflitos seus, aconteçam na adolescência. A luta por sua independência, o desligamento progressivo dos pais, as tentativas de se integrar a um grupo maior de colegas, tudo isso, apesar de não ser exclusivo dessa etapa da vida, são manifestações que compõem costumeiramente a crise em que a puberdade coloca o sujeito e que o filme novamente explora de maneira genial a partir das especificidades visuais de Leo e da maneira como ele experimenta sua idade.
Serão essas três dimensões da trama que abordaremos em nossa análise do filme. Partindo das discussões psicanalíticas, especialmente de Freud e Lacan, buscaremos estudar as reflexões que o filme nos permite fazer sobre a construção da sexualidade de cada um, pensando, sobretudo, como a cegueira e a adolescência participam das descobertas de Leo e de como uma e outra servem de metáforas para a relação que qualquer ser humano mantém com sua sexualidade - enxergue ou não, esteja na puberdade ou não, seja homossexual ou não.

\section{O intercâmbio impossível da adolescência}

Logo no início de Hoje eu quero voltar sozinho, Leo se desperta para um desejo curioso aos olhos de sua amiga Giovana (Tess Amorim): fazer um intercâmbio. Para iniciar nossa discussão, partiremos desses dois significantes que elegemos, não por acaso, para descrever o início da trama: "despertar" e "intercâmbio". Significantes que muito podem dizer da adolescência.

O primeiro deles é bastante presente na psicanálise dos jovens, principalmente por Lacan ter se valido do termo em uma de suas poucas referências à adolescência. Ao prefaciar a peça $O$ despertar da primavera, de Frank Wedekind, Lacan (1974/2003) destacará essa dimensão do despertar da sexualidade que, de certo modo, não 
deixa de estar presente já em Freud. Afinal, ao descrever o desenvolvimento da sexualidade humana, Freud começa por distinguir um primeiro momento em que a criança desde cedo se encontra com a sexualidade, o que a psicanalista argentina Alba Flesler (2012) chama, com base no tempo lógico lacaniano, de "o instante de ver", mas também de "o primeiro despertar da sexualidade". Freud sugere que esse primeiro momento seja procedido de um período de latência, quando a sexualidade que se despertou nos primeiros anos arrefece e, embora não deixe de estar presente, permite que o sujeito sofra importantes impactos da cultura: recalque, sublimação, formação de caráter, fantasia e os primeiros arranjos sintomáticos.

Flesler, ainda comparando o desenvolvimento freudiano com o tempo lógico lacaniano, sugere que pensemos o período de latência como um "tempo para compreender" que antecede a puberdade. Na puberdade, que é quando em Freud encontraremos um segundo encontro com a sexualidade, teríamos o que Flesler chamou de "momento de concluir", ou o "segundo despertar da sexualidade". Concluir aqui não significa acabar, mas decidir-se. É nesse momento que Leo se desperta para sua homossexualidade e conclui algo sobre seu desejo, o que não significa, insistamos, que o trabalho cessou.

Lacan, portanto, irá abordar a adolescência por meio da teatralização de um despertar. No já citado prefácio da peça de Wedekind, Lacan irá dizer que a sexualidade não faz sentido, ela faz furo no real. Afinal, o despertar que ocorre nas personagens adolescentes da peça é, para Lacan, um encontro com o real, principalmente com o real do sexo. Real que, como lembra o psicanalista Alexandre Stevens (2004), não pode ser resumido ao aumento hormonal que exige a expulsão dos líquidos sexuais, o que não provoca nenhuma crise relevante em um bezerro quando esse se transforma em touro. No ponto em que estamos, o real lacaniano deve ser entendido como o vazio de respostas para a pulsão sexual humana. Se os instintos dos demais animais nos fazem supor que entre eles há um saber fazer com a sexualidade, entre os animais humanos esse saber não existe e o púbere se encontra com esse vazio.

É a esse ponto que Freud chegou quando, em "Três ensaios sobre a teoria da sexualidade" (1905/1996), ele se propôs a responder se a homossexualidade se devia a questões inatas ou adquiridas. Afinal, deve-se a homossexualidade à genética ou a uma escolha? Depois de muitas voltas refutando tanto uma como outra alternativa, Freud chegará a conclusão de que é impossível esclarecer satisfatoriamente 
a origem da homossexualidade, mas que sua investigação o levava a uma questão ainda mais relevante do que essa. A investigação de casos considerados fora do padrão de sua época revelou ao pai da psicanálise que

há entre a pulsão sexual e o objeto sexual apenas uma solda, que corríamos o risco de não ver em consequência da uniformidade do quadro normal, em que a pulsão parece trazer consigo o objeto. Assim, somos instruídos a afrouxar o vínculo que existe em nossos pensamentos entre a pulsão e o objeto (Freud, 1905/1996, p. 140).

A conclusão a que Freud chega é que a pulsão não traz consigo seu objeto, na verdade ela sequer é dependente de seu objeto e sua origem não tem nada a ver com os encantos dele. Por isso não há uma resposta para a pulsão sexual, esse saber que nos demais animais é herdado filogeneticamente, no ser humano deve ser construído ${ }^{1}$. É por esse motivo que Freud, no fim de sua investigação sobre a homossexualidade, dirá que tal orientação sexual não se refere nem a uma questão inata nem apenas a algo adquirido. Não é nem uma determinação biológica nem uma escolha consciente, é uma construção, no máximo uma escolha forçada. Mas nisso ela não é diferente da heterossexualidade, que também é uma construção.

No entanto, ainda que Freud (1905/1996) insista na origem autoerótica da pulsão sexual, essa construção da sexualidade não é feita solitariamente. $\mathrm{Na}$ falta desse saber sobre a sexualidade, o sujeito busca um saber no Outro, mas esse saber falha, e é a essa falha do saber que o adolescente responde. Se o primeiro despertar da sexualidade e o primeiro encontro com o real são procedidos por um período de latência em que o sujeito encontra algumas respostas nos primeiros representantes do Outro (os pais ou os primeiros cuidadores), esse segundo despertar da sexualidade, que começa com a falha do Outro na puberdade, exige uma busca para além desses primeiros cuidadores, para além do lar. Daí o aparecimento do segundo significante destacado por nós: o intercâmbio. O segundo despertar exige um intercâmbio, uma troca (câmbio) com o que está fora (inter), para além do que é intrafamiliar.

O pai de Leo interpreta sua vontade de fazer intercâmbio como uma fuga dos conflitos familiares. Talvez ele não esteja totalmente errado, mas a questão parece um pouco mais complexa. Não se trata apenas de fugir, mas principalmente de encontrar, ou, mais precisamente, trata-se de procurar. Tatear o mundo fora do lar e quem sabe encontrar algum saber no Outro. Leo se sente preparado para isso, já não acredita nos exagerados riscos que seus pais parecem enxergar, principalmente por terem um filho cego, o que os conduz, sobretudo a mãe, a uma superproteção. Leo é cego, mas é suficientemente esperto para ver que os riscos existem, mas que ele apresenta condições de vivenciá-los. Uma cena no início da história é bastante ilustrativa: na mesa do café, Leo brinca de se equilibrar na 
cadeira enquanto seus pais o advertem do risco. Ele, jocosamente diz ter superpoderes, pois sempre fez isso e nunca caiu. Também quando retorna da festa da escola gripado, ele parece advertir os pais dizendo que é só um resfriado, coisa corriqueira, o risco não é tão grande quanto parece e talvez a recompensa seja valiosa. Por isso a insistência de Leo em se livrar da superproteção dos pais através de seus intercâmbios: ir às festas, às viagens da escola, acompanhar o amigo no eclipse, morar nos Estados Unidos. Leo já não se satisfaz com as respostas encontradas nos pais, é preciso se lançar para mais longe e ele sabe que não vai cair da cadeira facilmente como os pais supõem. Seu pai parece perguntar do que o filho está fugindo, mas a pergunta mais importante talvez seja o que Leo está procurando. Isso que pode ser encontrado em um amigo da escola, no passeio com os colegas, ou nos Estados Unidos. Não importa onde, o importante é que o intercâmbio aconteça, porque o saber do Outro intrafamiliar, como é próprio na puberdade, falhou.

Contudo, há algo de impossível nesse intercâmbio, e a impossibilidade se deve não ao fato de Leo ser um menino cego que traria problemas ao viajar sozinho para os Estados Unidos. Essa dificuldade é superada através de agências especializadas. A impossibilidade do intercâmbio se deve à, já mencionada, falta de resposta sobre nossa sexualidade. Mesmo no campo do Outro, que será onde o sujeito encontrará material simbólico para representar o objeto da pulsão, esse saber não se apresentará nunca por completo. Um dos ensinamentos de Freud é que a pulsão jamais poderá se satisfazer, pois jamais conseguirá representar o objeto a que visa. Como foi dito anteriormente, essa é a conclusão que Freud chega em 1905, mas que já estava presente em seu "Projeto para uma psicologia científica" (1950/1996), rascunhado em 1895, quando ele sugeriu que a pulsão visa uma Coisa (das Ding) perdida desde sempre. Se o objeto da pulsão está perdido desde sempre, então não é o caso dizer que ele esteja proibido, mas que ele é impossível.

Como alerta Coutinho Jorge (2010), "seria um erro subtrocar o âmbito do impossível pelo o do proibido" (p. 143). O objeto da pulsão, perdido desde sempre, está no âmbito do impossível, por isso nunca conseguirá ser representado no campo do Outro. É por esse mesmo motivo que estamos fadados a encontrar sempre um meio-saber para nossas exigências pulsionais, nunca um saber completo, definitivo, o que faz do trabalho de construção da sexualidade prosseguir por toda a vida. É nesse sentido que o intercâmbio de Leo, assim como o objeto perdido da pulsão, é impossível.

A impossibilidade desse intercâmbio foi formulada por Lacan (1972$73 / 1985)$ através de sua afirmação de que a relação sexual não existe. Jacques-Alain Miller e Eric Laurent (2005) lembram que quando Lacan se 
refere à inexistência da relação sexual o que ele diz é que a pulsão não encontra no campo do Outro nenhuma acomodação possível ou proporcional a sua exigência. Em outras palavras, o intercâmbio sexual entre a pulsão e o campo do Outro não acontece de forma integral, haverá sempre um resto da pulsão que não encontrará abrigo no Outro. Evidentemente, Lacan não está dizendo que não existe o ato sexual, mas que há uma disjunção entre a pulsão e o Outro até quando o ato sexual acontece. O que Lacan sugere é que a pulsão é inevitavelmente estranha ao Outro ao mesmo tempo que busca nele o objeto de sua satisfação. Vimos com Freud que a pulsão independe de seu objeto, porque seu objeto é desde sempre perdido, ou seja, Leo, assim como todos nós (porque Leo é todos nós), não encontrará esse objeto no Outro - nem no corpo de seu amigo, nem na linguagem, nem na cultura, nem mesmo fora do seu país.

É nesta perspectiva que Stevens irá dizer que a adolescência é um encontro com o impossível - um dos nomes lacanianos para o real -, pois, se o primeiro despertar da sexualidade foi procedido de um tempo de latência em que o sujeito encontrou, ainda que precariamente ou fantasiosamente, um arranjo simbólico e imaginário para suas pulsões parciais, a puberdade é o momento em que esse arranjo falha e que o real, enquanto aquilo que escapa ao simbólico e ao imaginário, aparece. Na puberdade, o Outro, tesouro do significante e por isso também provedor de sentido, falha, assim como também falham a fantasia, o pai e as identificações. Diante da falha do Outro, do encontro com a não relação sexual, o sujeito responde com um conjunto de sintomas que chamamos, desde o fim do século XVIII, de adolescência. Por isso Stevens afirma que a adolescência é um sintoma da puberdade. Poderíamos acrescentar, a adolescência é um intercâmbio impossível.

\section{Os intercâmbios, "todos os possíveis", da adolescência}

Vimos que a puberdade, ao provocar novamente o despertar da sexualidade, exige uma reatualização das escolhas sexuais, lançando o adolescente à tarefa de fazer um intercâmbio na tentativa de encontrar um destino para sua pulsão no campo do Outro, que inclui o pequeno outro, ou seja, seu semelhante, mas que também inclui toda a cultura, o mundo em que vive e mesmo os novos mundos que podem ser explorados, como é o caso da América do Norte na história de Leo. Não obstante, essa resposta buscada no intercâmbio é impossível, pois somos todos, em certa medida, "cegos" como Leo. A cegueira nesse sentido não é uma deficiência visual, dos órgãos dos sentidos, mas uma cegueira fundamental que nos impossibilita de ter acesso direto ao real. $\mathrm{O}$ acesso deixa 
de ser imediato e passa a ser mediado pelas leis da linguagem. Assim, não podemos nunca ver a Coisa (das Ding) visada pela pulsão, somente através das representações simbólicas e imaginárias que fazemos dela.

Se, por um lado, essa "cegueira" faz do intercâmbio algo impossível, por outro ela indica também que as possibilidades de arranjo são várias, quiçá infinitas. A impossibilidade de ver a Coisa, de ter acesso imediato ao real, exige uma representação. É por isso que para Lacan (1960/1997) das Ding "será sempre representada por um vazio, precisamente pelo fato de ela não poder ser representada por outra coisa - ou, mais exatamente, de ela não poder ser representada senão por outra coisa" (p. 162). Ou seja, para Lacan, das Ding está entre o impossível de se representar (o vazio) e as infinitas possibilidades de representação (outra coisa). Também é esse tipo de raciocínio que levará Stevens a dizer que a adolescência pode ser encarada tanto como a idade do encontro com o impossível quanto "a idade de todos os possíveis":

"Todos os possíveis" é a vertente da resposta ao encontro com um impossível. Que tudo seja possível do lado das respostas é, sem dúvida, exagerado, mas é verdadeiro que certos possíveis são, no momento da adolescência, abertos ou reabertos quanto à escolha da resposta (Stevens, 2004, p. 26).

Ao reatualizar suas escolhas na adolescência, o sujeito depara com a 
impossibilidade de "ver" a Coisa (das Ding). É impossível encontrar uma resposta adequada a suas vivências pulsionais. Se não há uma resposta adequada é porque todas as respostas são possíveis. Se o objeto é desde sempre perdido, se o perdemos de vista, então não podemos contar com um norte definitivo que nos oriente. É claro que isso não significa que o Outro não tenha nada a dizer sobre nossa sexualidade. Pelo contrário, o Outro diz muitas coisas tanto sobre nossas escolhas sexuais quanto nossas identificações com os gêneros. Aliás, tanto a escolha objetal quanto a identificação só são possíveis através do campo do Outro. No entanto acontece que nada do que o Outro diz, ou melhor, nada do que possamos encontrar no Outro, é definitivo, adequado, justo para a pulsão. É por isso que Stevens fala de abertura ou reabertura de certas possibilidades quanto à escolha das respostas que elegeremos para nossa sexualidade. É na puberdade, diante do fracasso do Outro, que o sujeito abre e reabre o campo das possibilidades existentes para sua sexualidade. Se esse campo de possibilidades tende a se fechar durante o período de latência, quando o Outro tenta dar uma resposta à sexualidade dizendo o que é o masculino e o feminino, na puberdade esse campo tende a se reabrir, para então, depois de certo trabalho, algo ser concluído, mesmo que nunca findado.

Esse trabalho sobre a sexualidade apresenta pelo menos duas vertentes que, em certa medida, coincidem com duas modalidades de amor destacadas por Freud. Para o psicanalista, o amor se apresenta tanto como desejo de ter o objeto, quanto desejo de ser o objeto. Essa leitura é encontrada, sobretudo, em "Psicologia de grupo e análise do ego" (1921/1996), quando o autor irá mencionar a prática canibal e a comunhão cristã como exemplos de tentativas de se identificar ao objeto através da incorporação oral deste. Os canibais ingerem seus inimigos mais admirados da mesma forma como os cristãos ingerem metaforicamente Cristo para se assemelharem a ele. Essa questão é ainda mais bem explicada poucos anos depois, quando Freud (1923/1996) diz que uma das formas do aparelho psíquico compensar a perda dos objetos é se identificando com eles, já que, quando o Eu se apresenta ao Isso semelhantemente ao objeto perdido, o Isso pode amar o objeto através do amor narcísico que sente pelo Eu. Ou seja, quando uma parte do psiquismo se assemelha ao objeto perdido, outra parte pode manter seu amor a despeito da perda objetal. Essas duas dimensões do amor, de ter o objeto e de se identificar com ele, também aparecerão como importantes vertentes na construção 
da sexualidade. Após analisar o caso de uma jovem homossexual, Freud (1920/1996) irá dizer que a sexualidade é sustentada não apenas pelos caracteres sexuais físicos, mas também pelos caracteres sexuais mentais e pelo tipo de escolha de objeto. A construção da sexualidade, então, não se apoiará somente nos caracteres físicos, mas principalmente na escolha objetal (ter) e na identificação com os gêneros (ser), o que novamente nem sempre coincidirá com as respostas pré-fabricadas pela sociedade. Isso porque no animal humano tanto a escolha objetal quanto a identificação carecem de uma resposta prévia dada de antemão pelos caracteres físicos e, portanto, ambas precisarão ser construídas.

Essa construção também aparece em Lacan quando sugere que cada ser humano terá de dar sua própria resposta à questão da existência e da sexualidade. Não há nada, a não ser no campo do imaginário, na ordem dos ideais, que responda ao sujeito o que é ser menino ou menina, homem ou mulher, nem quais objetos atendem à pulsão de um e de outro. Por isso, a diferença entre homens e mulheres, para Lacan, se jogará no nível do gozo: "Não sabemos o que seja o homem e a mulher, mas isto não significa que não exista. Por não sabermos o que seja é que faz com que cada sujeito tenha que responder a seu modo a esta questão em sua existência" (Lacan apud Leguil, 2013, p. 150) - a maneira como cada um vai operar com esse 
gozo é que irá situá-lo como sujeito. E existem vários modos de operar com esse gozo, várias possibilidades, ou mesmo todas as possibilidades, "todos os possíveis".

Essa diversidade do modo como o sujeito opera com o gozo é evidenciada por $\$ \diamond a$ Lacan (1966-67/2003, p. 325) também em sua fórmula para a fantasia. Ao pensar a fantasia como a junção e disjunção entre o sujeito dividido e o objeto $a$, Lacan reafirma a tese freudiana que supõe a perda de um objeto para a pulsão e indica que o objeto só poderá ser reinserido no circuito pulsional através da fantasia; em uma operação, portanto, que nada tem de natural, pois se trata de uma invenção. $\mathrm{O}$ matema da fantasia indica todas as relações possíveis e impossíveis do sujeito com o objeto $a$.

Um dos grandes trabalhos da puberdade será reconstruir essa fantasia diante do encontro com o impossível. $\mathrm{Na}$ puberdade, os primeiros arranjos fantasmáticos falham, por isso esse é um tempo de abrir e reabrir possibilidades e passar do âmbito do impossível para o que Stevens (2004) chama de "todos os possíveis". A particularidade da história de Leo é que ele terá que fazer esse trabalho sem contar com os estímulos visuais que por vezes guiam as escolhas objetais dos seres humanos. Leo terá que contar com outros objetos que lhe atingem o corpo para construir sua resposta. A cena dos dois amigos no cinema é um momento importante do filme. Sem poder enxergar o que se passa na tela, Leo se apega à voz do colega que lhe sussurra a cena. A voz apresenta uma dimensão simbólica que permite que ele construa uma narrativa, e mais que isso, a voz é um objeto que carrega algo do real, do puro som que independe de significação, e que desperta em Leo um afeto. Isso também acontece com o cheiro do moletom esquecido pelo amigo em sua casa. É a partir destes estímulos (sons, cheiros, toques) é que Leo transformará o intercâmbio impossível da puberdade em vários intercâmbios possíveis que o levarão, finalmente, ao amor.

No fim do filme, Leo encontra no amor a possibilidade de equacionar, na fantasia, o intercâmbio de sua puberdade. Com o encontro amoroso, Leo se relaciona fantasiosamente com o objeto $a$, seu objeto de gozo - identificado pelo cheiro e pela voz de seu parceiro. Como afirma Miller e Laurent (1997), na relação com o Outro, o amor não é estabelecido por nenhum instinto. Essa relação é mediada pelo sintoma e por isso "Lacan define o amor como o encontro, no parceiro, dos sintomas, dos afetos, de tudo o que nele e em cada um marca o rastro de seu exílio da relação sexual" (p. 156). É como uma marca desse tipo que podemos entender o lugar que os objetos, cheiro e voz, ocupam na relação de Leo e seu parceiro. O amor surge aí como uma espécie de miragem para o sujeito, um encontro com objetos que o ajudam a fazer suplência a não existência da relação sexual. 


\section{O intercâmbio do amor e a passagem do impossível ao necessário}

Se o encontro com o impossível, próprio da puberdade, revela algo de real - daquilo que não se deixa representar -, a dimensão de "todos os possíveis" nos remete ao campo do simbólico - do que pode ser representado de diversas maneiras. Como lembra Coutinho Jorge (2010), o real é definido por Lacan como algo que ex-siste, ou seja, que existe do lado de fora do Outro, que é impossível de ser escrito, mas que não cessa de não se escrever. Já o simbólico é o próprio discurso do Outro, que recusa a negação insistente do real - portanto, cessa de não se escrever - e dá alguma existência ao objeto. Porém, essa existência simbólica é precária e fugaz, e por isso pode ser alterada, o que abre as possibilidades e nos lança no "todos os possíveis" de Stevens. Por isso, se o impossível é um dos nomes do real, a contingência será também um dos nomes do simbólico.

Contudo, o filme não nos deixa apenas nessas duas dimensões da puberdade, entre o impossível e o contingente, entre o real e o simbólico, entre o que não cessa de não se escrever e o que cessa. O percurso de Leo nos mostra que o jovem alcança algo também da ordem do amor. Dissemos que para Lacan a relação sexual, o intercâmbio entre a pulsão e o Outro, é impossível. Porém, no mesmo seminário em que Lacan afirmará tal tese, ele também irá sugerir que para fazer suplência a essa não relação sexual é que lançamos mão do amor. $\mathrm{O}$ amor seria, por conseguinte, algo que tentaria estabilizar isso que é da ordem de "todos os possíveis". Por isso o amor não se apresentará na obra lacaniana nem como um impossível nem como uma contingência, embora todos os registros estejam presentes no amor. $\mathrm{O}$ amor, enquanto o que faz suplência a não relação sexual, aparecerá como um esforço em estabilizar de modo "definitivo" a escolha objetal, que de outro modo permaneceria impossível (registro do real) ou contingente (registro do simbólico). Por isso, o amor poderá ser situado no registro do imaginário, tornando a escolha objetal necessária, ou seja, que não cessa de se escrever. O encontro com "todos os possíveis", com a contingência, é substituído no amor por um intercâmbio necessário.

Todavia, é sempre importante lembrar que essa suplência à impossibilidade da junção entre a pulsão e o Outro não faz a relação sexual existir. A disjunção continua e é isso que significa alojar o amor no registro do imaginário. A estabilização do objeto escolhido que aparece como algo necessário é, na verdade, uma estabilização imaginária. Ela também pode se desestabilizar a qualquer momento e sabemos que o amor também se desestabiliza, muitas vezes por pouco, transformando novamente o que é necessário em impossível. Contudo, esse não é o caso 
do filme, pelo menos não no ponto em que ele nos deixa. O filme, ao seu modo, nos apresenta um happy end. Leo se apaixona por Gabriel (Fabio Audi) e é correspondido. Não sabemos o que acontecerá com o amor dos dois. Eles respondem às provocações dos colegas da escola, dando-se às mãos. Às cegas, como sempre temos que fazer, Leo começa a construir sua sexualidade e só assim inventa um amor. O intercâmbio impossível da relação sexual transforma-se no intercâmbio necessário do amor. A cena final parece nos sugerir exatamente uma mudança na ordem do impossível: após ter dito ao amigo que, devido ao seu comprometimento visual, seria impossível aprender a andar de bicicleta, Leo é visto pedalando e controlando o guidão da bicicleta de Gabriel, mas não sem seu parceiro amoroso por perto lhe orientando. No fim do filme, o impossível acontece, para isso é preciso algum laço, ainda que imaginário. No entanto, ainda que o filme nos ofereça através do amor um happy end, não podemos deixar de advertir, como o faz Miller e Laurent (2005), que na experiência do amor o sujeito não conhece a regra do jogo e por isso terá sempre que se perguntar: com quem se joga a partida?

\section{Abstract}

THE IMPOSSIBLE EXCHANGE OF ADOLESCENCE: A PSYCHOANALYTIC ANALYSIS OF THE AWAKENING OF SEXUALITY THROUGH THE MOVIE "THE WAY HE LOOKS", BY DANIEL RIBEIRO
This paper discusses, from the movie The way he looks, by Brazilian director Daniel Ribeiro, the way psychoanalysis thinks human sexuality, always viewing it as a construction. For this reflection, three aspects of the film will be highlighted: the awakening of the protagonist's homosexuality, his blindness and his passage through adolescence. These aspects are related to each other through concepts of Freud and Lacan to address the relation between drive and its object.

Index terms: cinema; sexual drive; homosexuality; adolescence; psychoanalysis.

\section{RESUMEN}

EL INTERCAMBIO IMPOSIBLE DE LA ADOLESCENCIA: ANÁLISIS PSICOANALÍTICO DEL DESPERTAR DE LA SEXUALIDAD A TRAVÉS DE LA PELÍCULA "HOY QUIERO VOLVER SOLITO” DE DANIEL RIBEIRO

Elpresente articulo tiene por objetivo discutir, a partir de la película, Hoy quiero volver Solito del director brasileño Daniel Ribeiro, la manera como el Psicoanálisis piensa la sexualidad humana, enfrentándola siempre como una construcción. Para esa reflexión, se destacaran tres aspectos de la pelicula: La homosexualidad del protagonista, su ceguera y sus pasos por la adolescencia. Estos aspectos serán relacionados entre sí mediante conceptos de Freudy Lacan que abordan la relación entre la pulsión sexual y su objetivo.

Palabras clave: cinema; deseo sexual; homosexualidad; adolescencia; psicoanálisis.

\section{REFERÊNCIAS}

Coutinho Jorge, M. A. (2010). Fundamentos da Psicanálise de Freud a Lacan vol. II: A clinica da fantasia. Rio de Janeiro, RJ: Zahar.

Flesler, A. (2012). A psicanálise de crianças: $e$ o lugar dos pais. Rio de Janeiro, RJ: Zahar.

Freud, S. (1996). Três ensaios sobre a teoria da sexualidade. In S. Freud, Edição standard brasileira das obras psicológicas completas de Sigmund Freud (J. Salomão, trad., Vol. 
7, pp. 117-229). Rio Janeiro, RJ: Imago. (Trabalho original publicado em 1905)

Freud, S. (1996). Psicologia de grupo e análise do ego. In S. Freud, Edição standard brasileira das obras psicológicas completas de Sigmund Freud (J. Salomão, trad., Vol. 18, pp. 13-78). Rio Janeiro, RJ: Imago. (Trabalho original publicado em 1921)

Freud, S. (1996). A psicogênese de um caso de homossexualismo numa mulher. In S. Freud, Ediçâo standard brasileira das obras psicológicas completas de Sigmund Freud (J. Salomão, trad., Vol. 18, pp. 155-183). Rio Janeiro, RJ: Imago. (Trabalho original publicado em 1920)

Freud, S. (1996). O Ego e o Id. In S. Freud, Edição standard brasileira das obras psicológicas completas de Sigmund Freud (J. Salomão, trad., Vol. 19, pp. 15-82). Rio Janeiro, RJ: Imago. (Trabalho original publicado em 1923)

Freud, S. (1996). Projeto para uma psicologia científica. In S. Freud, Edição standard brasileira das obras psicológicas completas de Sigmund Freud (J. Salomão, trad., Vol. 1, pp. 335-440). Rio Janeiro, RJ: Imago. (Trabalho original publicado em 1950)

Lacan, J. (1985). O seminário, livro 20: mais, ainda, 1972-1973. Rio de Janeiro, RJ: Jorge Zahar.

Lacan, J. (1997). O seminário, livro 7: a ética da psicanálise, 1960. Rio de Janeiro, RJ: Jorge Zahar.

Lacan, J. (2003). A lógica da fantasia In J. Lacan, Outros Escritos (pp. 323-28). Rio de Janeiro, RJ: Jorge Zahar. (Trabalho originalmente publicado em 1966-67)

Lacan, J. (2003). Prefácio a O despertar da primavera. In In J. Lacan, Outros Escritos. Rio de Janeiro, RJ: Jorge Zahar. (Trabalho original publicado em 1974)

Leguil, C. (2013). Matrimonio para todos. Nuevo campo de batalla para el psicoanálisis. In Transformaciones. Ley, diversidad, sexuación (pp. 145-58). Buenos Aires: Grama.
Miller, J.-A., \& Laurent, E. (1997). A teoria do parceiro. In O Outro que náo existe e seus comitês de ética (pp. 153-207). Seção Clinica: Paris VIII.

Miller, J.-A., \& Laurent, E. (2005). El Otro que no existe y sus comités de ética. Buenos Aires: Paidos.

Schopenhauer, A. (2003). Metafísica do belo. São Paulo, SP: Editora UNESP.

Stevens, A. (2004). Adolescência, sintoma da puberdade. Revista Curinga: Clínica do Contemporâneo, 20, 27-39.

\section{NOTA}

1. Reside aí a principal distinção entre as palavras Instinkt e Trieb que Freud utiliza, ainda que com algumas imprecisóes, como forças internas diferentes que guiam o animal e o homem. Se o instinto pressupóe um conhecimento herdado filogeneticamente que coloca o animal em busca dos objetos naturais para sua sobrevivência, a pulsão, possível tradução para Trieb, não encontraria um objeto natural que o satisfizesse, mas suportaria uma infinidade de objetos que só se ligariam à pulsão por meio de um jogo simbólico.

beto7296@yahoo.com.br Rua Cedro, 317/701 35160-296 - Ipatinga - MG - Brasil. virginiasoutomaior@yahoo.com.br Rua Jequitibá, 299 35160-306 - Ipatinga - MG - Brasil.

Recebido em dezembro/2014. Aceito em fevereiro/2015. 